\title{
NORMATIVIDADE E POLÍTICAS EDUCACIONAIS: BASES PARA UMA ABORDAGEM DA LDB E DA CONAE
}

\author{
SidNEy REINALdo SiLVA*
}

\begin{abstract}
RESUMO: Este texto aponta bases normativas para a análise de políticas educacionais a partir da teoria da justiça e de sua correlação com a democracia, operando uma contraposição de autores como Rawls, Honneth e Fraser. Parte-se de uma apresentação do modelo liberal e de sua proposta de redistribuição. Em seguida, abordam-se críticas a esse modelo feitas pela teoria do reconhecimento de Honneth. São descritas, posteriormente, a crítica e a rearticulação desses modelos na obra de Fraser, apresentando a sua concepção de participação como base normativa para as políticas sociais. A partir da reconstrução dos referidos modelos normativos, foram indicadas questões referentes à Lei de Diretrizes e Bases da Educação Brasileira (Lei n. 9.394 de 1996) e ao Documento Final da Conferência Nacional de Educação (Conae), de 2010.
\end{abstract}

Palavras-chave: Distribuição. Reconhecimento. Participação. LDB. Conae.

\section{Normativity AND EDUCATIONAL POLICIES: FOUNDATIONS FOR A LDB AND CONAE INVESTIGATION}

\begin{abstract}
This paper aims to point out some normative foundations for analyzing the educational policies and its connection with justice theory and democracy, for this purpose we confront normative standpoint of authors like Rawls, Honneth and Fraser. The paper begins presenting the liberal model and its proposal of redistribution, then we tackle Honneth's critiques of the liberal point of view and the critical perspective of Fraser against the liberals' unilateralism and his recognition of theories about justice as well as his conception about participation as a normative base. At last, after the reconstruction of the mentioned models, it is shown how the normative question arises from the LDB and the National Conference on Education (Conae) and how instigating and heuristic this issues are for a democratic discussion about what kind of education Brazilian people want and need .
\end{abstract}

Key words: Distribution. Recognition. Participation. LDB. Conae.

Doutor em Filosofia, professor do Programa de Pós-Graduação em Educação da Universidade Tuiuti do Paraná (UTP) e professor de Filosofia do Instituto Federal de Educação, Ciência e Tecnologia do Paraná (IFPR). E-mail: sreinald@uol.com.br 
Normativité et politiques éducatives:

BASES POUR UNE INVESTIGATION DE LA LDB ET DE LA CONAE

\begin{abstract}
RÉSUMÉ: Ce teXTE INDique des bases normatives pour l'analyse des politiques éducatives en partant de la théorie de la justice et sarelation avec la démocratie et du contraste théorique entre divers auteurs comme Rawls, Honneth et Fraser. On commence par une présentation du modèle libéral et de son projet de redistribution. Ensuite, on présente les critiques de la théorie de la reconnaissance de Honnet, adressées à ce modèle. On présente par la suite la critique et la reformulation de ces modéles dans l'oeuvre de Fraser, en présentant sa conception de participation comme base normative pour les politiques sociales. Finalment, sont soulevées, selon la reconstruction de ces modèles normatifs, des questions à propos de la Loi de Directives et Bases de l'Éducation Nationale (n. 9394/96) et du Document Final de la Conférence Nationale d'Éducation (Conae) de 2010.
\end{abstract}

Mots-clés: Distribution. Reconnaissance. Participation. LDB. Conae.

\title{
Introdução
}

$\mathrm{N}$

uma sociedade democrática, quando a reprodução da sociedade civil depende de alguma forma de intervenção do Estado, o debate normativo se faz necessário. No caso da educação, isso se faz presente quando se indaga qual o tipo de sociedade se quer e qual formação é devida para inserir as pessoas no mundo do trabalho e da cidadania. A racionalidade da vontade coletiva define-se por certo bem e certa moldura da justiça, correlatos de valores e princípios, orientações e modulações das decisões públicas e privadas. Frente a isso, pode se indagar como e por que em certos momentos uma base normativa ganha destaque frente às demais e, de certo modo, está ligada aos rearranjos políticos e institucionais de um país.

Recentemente, a "demanda" por reconhecimento tem se destacado no cenário político. A política do reconhecimento surgiu frente à crise do socialismo enquanto horizonte de luta social anticapitalista. Ela tem sido condizente com a globalização dos movimentos sociais vinculados à questão ecológica, de gênero, de etnia, com a fragmentação e reticulação da luta pela emancipação, sendo coetânea da crise do Estado de bem-estar social e das políticas de redistribuição liberal, bem como de novas formas de participação política local em fóruns e espaços colegiados de gestão. Frente ao debate entre teorias da justiça, questões sobre a educação podem ser colocadas no sentido de buscar bases de justificação para as políticas que a afetam. Que tipo de relação ético-política há entre democracia, teoria da justiça e políticas educacionais? Em que sentido categorias normativas ajudam a compreender o que se faz e a propor o que se deve fazer em educação? Como enfocar crítica e normativamente as Leis de Diretrizes e Bases da Educação, Lei n. 9.394/96, e a Conferência Nacional de Educação (Conae)? 
Devido ao curto espaço deste artigo, limitou-se ao apontamento da pertinência da análise normativa, sem apresentar considerações críticas, ou seja, apontamentos sobre seus limites, seu caráter ideológico, ou a quem de fato ela serve e como ela pode "colocar o carro na frente dos bois".

\section{Liberalismo e redistribuição}

Os liberais afirmam a democracia como a melhor forma de garantir os seus valores centrais: a liberdade pessoal, o pluralismo social e o constitucionalismo político. Contudo, tais valores são postos como uma forma de proteção liberal contra a própria democracia, ou seja, as transformações sociais indesejadas (não liberais) que, por ventura, ela poderia engendrar. As exigências a favor da igualdade social ou da soberania popular devem ser construídas com base nesses valores, pois elas não são parte desses fundamentos centrais (FORST, 2010, p. 48).

Umas das formas de justificar a democracia liberal é a afirmação de que ela tem como arcabouço uma estrutura procedimental que visa garantir um diálogo razoável (desacordo e tolerância entre tolerantes contra os intolerantes, ou os que não aceitam os princípios liberais). O diálogo liberal é assegurado pela via do recurso a princípios cuja não aceitação, afirma-se, não seria razoável independente das convicções éticas, de vida boa ou de bem às quais alguém se filia ou nas quais foi formado. Assim se fala na prioridade do justo (arcabouço jurídico, regras procedimentais) sobre o bem (valores éticos, vontade popular, concepções de bem viver e de objetivos de vida) como moldura do procedimento democrático.

Contudo, isso não deixa de ser uma blindagem "ética" contraditória, pois tais princípios procedimentais da "justa" deliberação não deixam de ser um "bem", a ser levado em conta em primeiro lugar, o que torna o liberalismo numa espécie de tradição comunitária, como tem acentuado Taylor (2000). No entanto, para os liberais, a questão da neutralidade procedimental tem sido considerada como um modo de evitar que o bem, tal como o entende Rawls, se imponha ou tenha precedência sobre o justo. Korsgaard $(1996$, p. 8) refere-se ao direito (right), no caso o justo, como algo necessário moralmente, ou seja, que tem que ser feito (that you ought to do it) e ao bem (good) como aquilo que pode ser objeto de recomendação preferência, quer dizer, algo que vale a pena ser escolhido (worthy of your choice). Essa é uma linha de corte fundamental para se compreender a diferença entre a teoria da justiça liberal e a comunitarista. Prevalece entre os liberais a prioridade do justo sobre o bem como uma condição de possibilidade do pluralismo democrático.

Para os liberais, o justo seria também uma garantia da igual consideração e respeito para todos perante o público e a lei. Frente ao justo, se aceita então falar da necessidade ou valor da igualdade. A justiça liberal admite a redistribuição de 
recursos sociais para assegurar a igualdade de oportunidades, desde que isso não seja feito para promover um tipo específico de vida boa ou de bem. Com isso, os liberais buscam limitar a ação do Estado de modo a evitar que ele se comprometa com alguma concepção de bem. Nesse sentido, o princípio da neutralidade exige a pluralidade e vice-versa (FORST, 2010).

Os liberais aceitam promover a redistribuição de renda e bens sociais em nome da promoção do direito ao igual tratamento frente às instâncias públicas. A redistribuição não é um bem em si, pois a igualdade de condições sociais não é um princípio liberal, mas isso não significa que não se possa falar de uma igualdade liberal calcada no justo. Deve se lembrar de que nem todos os que podem ser enquadrados como liberais admitem a necessidade ou valor da redistribuição. Nozick afirma que o indivíduo tem direito a si mesmo e aos frutos de seu trabalho, bem como aos bens que conseguiu de acordo com regras justas de aquisição e transferência, sendo que qualquer forma de imposto voltado para compensar os que são menos privilegiados seria uma violação pública dos direitos da pessoa (KYMLICKA, 2006).

Contudo, os considerados liberais igualitários, diferentemente de Nozick, afirmam a necessidade moral da redistribuição. Admitem que, para tratar as pessoas como iguais, certos direitos e liberdades delas deveriam ser protegidos, e isso exige compensações. O princípio da diferença de Rawls (1971), paradoxalmente, ao procurar justificar as desigualdades sociais e econômicas, o faz no sentido de promover maior igualdade. É central, portanto, a distribuição dos bens primários sociais (a liberdade, oportunidade, renda, riqueza e uma base de respeito de si mesmo) de forma equitativa. Só se poderia aceitar uma distribuição desigual desses bens, desde que ela seja vantajosa para os menos favorecidos: deve se tratar as pessoas como iguais, não removendo todas as desigualdades, mas apenas as que trazem desvantagem para alguém (KYMLICKA, 2006). Desse modo, seriam toleradas desigualdades que beneficiassem todo mundo, se elas fomentassem talentos e energias socialmente úteis. Não seria injusto, diz-se, que certos profissionais, que tiveram uma formação mais dispendiosa em termos de dedicação e esforço, ganhassem mais do que aqueles cujo preparo não foi tão custoso. Mas, de acordo com a ordem de prioridade liberal, defendida por Rawls, as liberdades iguais têm precedência sobre a igualdade de oportunidade, que, por sua vez, teria prioridade sobre distribuição igual de recursos. As últimas só poderiam ser fomentadas publicamente se, de certo modo, promovessem a primeira (idem, ibid.).

Segundo Rawls, não seria justo que indivíduos sejam favorecidos ou não em decorrência de situações sociais ou circunstâncias que não escolheram. Cabe ao poder público corrigir ou compensar as desigualdades imerecidas. Assim ninguém merece nascer com alguma "deficiência", ou em uma classe social, grupo étnico ou 
sendo de um determinado gênero. Admite-se que os talentos "naturais e mesmo as circunstâncias sociais des/favoráveis referem-se a 'sorte bruta"' e esta não pode definir os direitos morais das pessoas (KYMLICKA, op. cit., p. 72). Do ponto de vista da equidade, os mais talentosos merecem ganhar mais apenas quando suas atividades fizerem parte de um esquema que melhora a situação dos menos favorecidos. Essa ponderação entre sorte e mérito passa a ser critério também para se investir em educação tanto daqueles menos privilegiados pela "sorte bruta", quanto dos que foram abandonados por ela. Assim, quem nascesse em uma classe ou etnia desfavorecida no contexto histórico de uma determinada sociedade não poderia ser privado dos benefícios sociais (bens primários), pois teriam direito de ser compensados por causa dessa desvantagem não merecida (idem, ibid.).

O que Rawls procura garantir é que todos tenham direito a bens primários, a mínimos sociais, definidos a partir de critérios políticos de justiça que levem em conta as pessoas como entidades públicas, ou seja, consideradas como seres livres e iguais independente das características que as diferenciam na vida cotidiana, como questões de classe social, etnia, gênero e religião. Os bens primários deveriam proporcionar a todos os cidadãos uma vida decente como seres razoáveis (que aceitam os princípios liberais, o diálogo como base da democracia deliberativa e, até um ponto mínimo, a primazia do justo sobre o bem) e racionais (capazes de ter um projeto de vida e de articular meios e recursos para realizá-los, responsabilizando-se por suas escolhas, sendo também capazes de tomar parte de um bem partilhado por uma comunidade - religiosa, política, artística, esportiva, acadêmica -, bem como de optar por recusar tal bem, escolhendo outros modos de viver conforme seu livre entendimento e questionamento das coisas).

O desenvolvimento dessas duas capacidades morais exige a garantia de uma distribuição igual de bens primários considerados, portanto, como socialmente básicos, pois deles dependem a própria estabilidade de uma sociedade justa. Contudo, isso não deve ser feito em nome de nenhuma diferença de identidade não política/cívica de indivíduos e grupos. Da forma como o justo se articula com o bem, deduz-se a necessidade de uma formação básica da racionalidade e da razoabilidade, condições para se julgar, respectivamente, sobre o bem e o justo.

Negar a redistribuição de rendas ou promovê-la a partir da garantia de mínimos sociais decorre do mesmo princípio normativo de garantia da autonomia liberal, que exige a prioridade do justo sobre o bem. Contudo, tanto a negação quanto a oferta de mínimos sociais podem afetar a estima social de alguém. Quando uma pessoa não pode trabalhar e não recebe recursos do poder público para manter-se, sua dignidade é afetada tanto por não poder contribuir de forma produtiva, quanto por não ser levado em conta enquanto sujeito de direito à vida e à segurança socioeconômica. Mas receber recursos públicos de forma "privilegiada" devido a desvantagens 
associadas ao gênero, etnia ou outro fator diferenciador pode ser, para os liberais, não só algo injustificável publicamente (em relação ao valor da universalidade e do igual tratamento), mas algo que submete a pessoa a alguma forma de tutela ou caridade pública humilhante. Daí que a proposta de uma renda mínima universal, independente de se estar trabalhando ou mesmo de se querer trabalhar, parecer mais condizente com a igual dignidade da pessoa humana, conforme defende certos liberais igualitários (VAN PARIJS, 1997). Para estes, o trabalho não é levado em conta como índice do mérito da pessoa.

A defesa das políticas de redistribuição e sua negação não se associam necessariamente com a produção da estima social. Segundo Honneth (2003b), esta é uma forma superior de solidariedade social, que extrapola efeitos meramente econômicos e de bem-estar social. O conflito em torno do reconhecimento diz respeito às condições de autorrealização da pessoa como membro que específica e efetivamente contribui para a prosperidade social e é afirmado como tal pela coletividade. No âmbito da estima social, o trabalho é retomado por Honneth como fundamental para a autorrealização. Este autor aborda o trabalho a partir das exigências normativas do reconhecimento. A seguir, retoma-se o debate travado entre Honneth e Fraser, que apontam para novas dimensões da normatividade, avançando em relação à abordagem reducionista da redistribuição nos debates sobre a justiça entre os liberais "libertários" e "igualitários".

\section{A prioridade do reconhecimento}

A tradição hegeliana do reconhecimento também valoriza a autonomia. Contudo, ela está relacionada com a promoção de um bem, ou seja, as condições da autorrealização humana. Honneth (2003a) diz que sai da rota kantiana, pois para ele não se pode afirmar o respeito universal à autonomia moral do ser humano sem por também como necessária as suas condições de autorrealização. Para ele, o reconhecimento tem primazia ético-política sobre a redistribuição. O gozo da liberdade jurídica (direito abstrato) e a possibilidade de avaliação reflexiva de seus atos (moralidade) não são suficientes para promover a autorrealização do sujeito. Werle e Melo (2007, p. 41) lembram que os limites da liberdade jurídica está na forma como ela "conta apenas com um mínimo da personalidade de cada um", ao passo que os limites da moralidade se dão devido a sua circunscrição no âmbito de "uma ação 'vazia' e cega em face dos 'contextos sociais de sua aplicação'”, abstraindo-se do "ambiente social dos conflitos práticos em que o ponto de vista moral já se encontra institucionalizado". Assim, sem experimentar condições sociais adequadas de reconhecimento, o sujeito não se liberta do sofrimento de indeterminação, o que se dá na esfera da eticidade marcada por práticas comunicativas. Esta libertação diz 
respeito à formação bem-sucedida do indivíduo no âmbito das esferas ou padrões do reconhecimento (idem, ibid., p. 42). Sem levar isso em conta, a redistribuição pode produzir reificação ou distorção do reconhecimento.

A formação depende de condições sociais e institucionais dadas como uma ordem justa que possibilita aos indivíduos participarem em práticas (relações comunicativas) experimentadas como expressão de sua liberdade. Contudo, lembra Honneth (2007) que as relações comunicativas são como uma espécie de bens básicos sem os quais as pessoas não realizam sua liberdade. Tais bens são indispensáveis na formação de uma pessoa como membro reconhecido de uma sociedade. A situação de reconhecimento para um indivíduo ou grupo designa o conjunto de condições intersubjetivas que permitem a este indivíduo ou grupo referir positivamente a si mesmo e ter uma representação positiva de sua própria identidade (Fischerbach, 1999). Ofensas morais, desrespeito social, desprezo comunitário e exclusão da participação política revelam experiências de não reconhecimento que atingem a estima de si que um indivíduo ou grupo deveria possuir, atingindo a dimensão ética, jurídica, cidadã e moral da pessoa (FORST, 2010).

Honneth (2003a) estabelece os seguintes padrões de relação de reconhecimento em sua diferenciação histórica dada pelas seguintes etapas: o amor, o direito e a solidariedade. $\mathrm{O}$ amor constitui-se na esfera primária do reconhecimento dado pelo sentimento de afeição mútua. A família e o casamento são instituições caracterizadas por esse padrão afetivo que diz respeito "as relações primárias, na medida em elas consistam em ligações emotivas fortes entre dois parceiros, de amizade e de relações pais/filho" (2003a, p. 159). No amor, os seres humanos se identificam como carentes e dependentes um do outro, ao confirmarem-se como necessitando de atenção e cuidado como manifestação de sentimentos de estima especial entre si. Nessa interação em que se manifesta um "equilíbrio precário entre autonomia e ligação", o conceito de amizade expressa o amor como uma forma de "ser-si-mesmo-em-outro", marca da natureza intersubjetiva do eu. $\mathrm{O}$ mesmo se dá na relação afetiva entre amantes e no cuidado recebido pela criança nos diversos ambitos institucionais. Uma experiência bem-sucedida de reconhecimento no âmbito do amor é decisiva para a formação da autoconfiança individual, considerada um pré-requisito para os outros modos de reconhecimento (o jurídico e a estima social), bem como uma "base indispensável para a participação autônoma na vida pública" (ibid., p. 178).

$\mathrm{Na}$ esfera do direito, o reconhecimento mútuo propicia o sentimento de ser uma pessoa com pretensões jurídicas asseguradas socialmente, de modo que pode reclamá-las quando sentir necessidade disso, da mesma forma que reconhece aos outros semelhante prerrogativa. Isso pode ser verificado, de certo modo, já nas relações pré-modernas de status de um indivíduo como participante de uma corporação de ofício, na qual ele se sente na qualidade de um membro social segundo sua posição 
definida pela divisão do trabalho (HONNETH, op. cit., p. 181). Na modernidade, o sistema jurídico passa a expressar os interesses universalizáveis de todos os membros da coletividade. A interação social torna-se pautada por regras que os parceiros assentiriam como pessoas livres e iguais: "reconhecendo a mesma lei, os sujeitos de direito se reconhecem reciprocamente como pessoas capazes de decidir com autonomia individual sobre normas morais" (idem, ibid., p. 182). A moralidade kantiana é uma base para a cidadania moderna.

A tipologia de Marshall também é retomada por Honneth para explicar a forma como a esfera jurídica do reconhecimento foi se estendendo do âmbito dos direitos liberais de liberdade para os direitos políticos e direitos sociais de bem-estar que constituíam diferentes manifestações dos direitos subjetivos (ibid., p. 189). O reconhecimento mútuo na esfera do direito exige de um sujeito, para que ele seja respeitado, a necessidade de encontrar "reconhecimento jurídico não só na capacidade abstrata de poder orientar-se por normas morais, mas também na propriedade concreta de merecer o nível de vida necessário para isso" (p. 193). Nesse sentido, o Estado de bem-estar social, onde ele se efetivou, garantiu os direitos sociais sem os quais o cidadão não poderia gozar das outras pretensões jurídicas conquistadas (p. 192).

O respeito de si decorre do reconhecimento jurídico, assim como a confiança em si advém do reconhecimento afetivo (HONNETH, 2003a, p. 195). A estima de si liga-se à esfera da solidariedade ou da estima social. Se, na esfera do direito, destacase a consideração do indivíduo com um fim em si mesmo, sem distinção baseada em mérito, desempenho ou traço pessoal específico, na esfera da solidariedade, destacase o respeito social como uma forma de salientar o valor de um indivíduo a partir de critérios éticos de relevância, que evidenciam as realizações pessoais reconhecidas socialmente como dignas de estima. A estima social "permite a um indivíduo referir-se positivamente a suas propriedades e capacidades concretas" (idem, ibid., p. 198). Contudo, isso depende de uma comunidade de valores ou horizonte avaliativo (eticidade). Frente a isso, a formação para o trabalho e as condições sociais para se integrar produtivamente configuram-se num fator fundamental para a constituição da autoestima, o que é normativamente inseparável das expressões culturais e simbólicas dos indivíduos, grupos e classes sociais. Para Honneth, o trabalho formalizado é base para a autorrealização humana, pois ele permite a uma pessoa expressar seu valor e ser reconhecido como alguém que contribui produtivamente para com a sociedade. Relações de reconhecimento não se desvencilham da distribuição e organização social do trabalho (HONNETH, 2008). O autor critica a forma como, no contexto capitalista, socialmente patológico, o trabalho não deixa de produzir alienação, como pode se verificar historicamente com o taylorismo e os ajustes posteriores da produção que primaram pela fragmentação das atividades laborais, destituindo-as de significação e de potencial de autorrealização (idem, ibid.). 
Honneth mostra que, tanto no caso do reconhecimento jurídico quanto no da estima social (reinterpretada posteriormente como solidariedade), "um homem é respeitado em virtude de determinadas propriedades, mas no primeiro caso se trata daquela propriedade universal que faz dele uma pessoa; no segundo caso, pelo contrário, trata-se das propriedades particulares que o caracterizam diferentemente de outras pessoas" (2003a, p. 187). Na esfera da estima social, está em questão "como se constitui o sistema referencial valorativo no interior do qual se pode medir o 'valor' das propriedades características" (ibid., p. 187), que fazem a diferença de cada um.

A estima social é definida pela autocompreensão cultural de um povo que estipula os critérios segundo os quais as capacidades e realizações serão avaliadas intersubjetivamente. Honneth (2003a) mostra que quanto mais aberta a diversidades dos valores e menos sujeita a uma hierarquização, mais a estima social ganharia características individualizantes e afirmaria relações simétricas. Em sociedades estamentais marcadas pelo princípio da honra, o valor do indivíduo é medido pela sua adequação a um determinado status social. Já nas sociedades modernas, as concepções de reputação ou prestígio social voltam-se para a individualização de quem contribui para as realizações das finalidades éticas da comunidade (idem, ibid.), ocorrendo uma abertura dos valores que definem as formas de autorrealização. A estima social, nas sociedades burguesas, passa a se referir à realização dos indivíduos na estrutura da divisão do trabalho industrialmente organizado, tendo como referência a ideia de cidadão produtivo num contexto de meritocracia (HONNETH, 2003b).

A partir da noção de estima social, Honneth aborda a solidariedade como relações simétricas entre sujeitos autônomos e individualizados. Ela apresenta-se como considerações recíprocas segundo as quais as capacidades e as propriedades específicas do outro são reconhecidas como estimáveis para a coletividade em sua praxis comum. Nas relações simétricas, o sujeito conta com condições não hierarquizadas ou sem gradações coletivas (estamentos) para a sua autorrealização, no sentido de poder provar o seu próprio valor para si e para ou outros (2003a).

Injustas ou indignas são as regras institucionais apontadas como violentadoras do reconhecimento. Isto está na base do conflito social normativamente motivado: "nas sociedades modernas, as relações de estima social estão sujeitas a uma luta permanente na qual os diversos grupos procuram elevar, com meios da força simbólica e em referência às finalidades gerais, o valor das capacidades associadas à sua forma de vida" (HONNETH, 2003a, p. 207). Destacam-se, num primeiro plano, as exigências de reconhecimento que melhoram a situação de membros individuais de um grupo pelo acesso a direitos básicos universais, ou aquelas baseadas na igualdade de consideração jurídica, que, contudo, acabam por exigir uma "abstração das diferenças culturais" (idem, ibid., p. 164). Mas são diferentes as exigências com dimensão comunal que visam proteger ou melhorar a vida comum enquanto grupo determinado. Há 
ainda movimentos sociais em torno de exigências que garantam a "coesão da comunidade", reivindicando, por exemplo, apoio econômico para a instrução na língua nativa, bem como uma adequada imagem na mídia. Da mesma forma as desvantagens passadas e presentes exigem medidas para eliminar obstáculos que injustamente as provocam. Semelhantes demandas só deixam de ter sentido quando essas injustiças são corrigidas.

Um terceiro tipo de conflito expressa com maior força o sentido identitário da luta pelo reconhecimento. Trata-se de exigências em torno do bem-estar comum de um grupo em sua especificidade que promovam um reconhecimento de seus objetivos ou valores "como tal". Não se demanda apenas iguais direitos políticos, "mas também de oportunidades de receber atenção pública para a própria convicção de valores específicos de grupo" (2003a, p. 167). Reconhece-se, então, que determinada cultura constitui um bem que deve ser apreciado pela sociedade. A estima não se relaciona com algum mérito ou desempenho, segundo uma escala liberal capitalista, mas como "algo que é socialmente valioso em si mesmo - como um bem social" (idem, ibid.).

Honneth (2003a) refere-se a abordagens dos sofrimentos cotidianos de humilhação e desrespeito ou pré-políticos, experiências que não afloram na arena política e não ganham o espaço público da democracia oficial. Para ele, as teorias da justiça altamente formalizadas são obras de elites que buscam justificar certa forma de sociedade, e seus princípios positivamente formulados não mobilizam a luta dos oprimidos. Os protestos das classes subalternas são motivados pela experiência e o sentimento de violação do que compreendem intuitivamente por justiça. Essa experiência permeia também os movimentos sociais de minorias que expressam a luta pelo reconhecimento da integridade pessoal, ancorada nas exigências ligadas à identidade (idem, ibid.), que dificilmente são assumidas na agenda das políticas públicas. O reconhecimento apresenta-se como o fator moral para se compreender as lutas pela participação nos espaços públicos e pela exigência de redistribuição. Em relação a isso, Fraser busca superar falhas apontadas ao modelo do reconhecimento, destacando a importância da incorporação da distribuição e da participação no espaço público como formas de promover a justiça não meramente subordinadas ao reconhecimento, mas articuladas com este.

\section{Exigências normativas da participação}

Fraser (2003) definiu a participação como base normativa para se correlacionar democracia e justiça social, articulando distribuição e reconhecimento num mesmo nível de prioridade, indicando uma co-originalidade das mesmas. Ela parte da constatação de que o princípio da distribuição tem sido indevidamente negligenciado 
ultimamente frente à proeminência da política de identidade. A autora destaca que as exigências de distribuição de riquezas e recursos entre o Norte e o Sul, entre ricos e pobres e entre proprietários capitalistas e trabalhadores assalariados, devem se rearticular com as políticas de reconhecimento, que visam resgatar o valor pago pelas minorias para receber respeito igual cobrado na forma de submissão ou de assimilação das normas da cultura dominante majoritária.

Fraser pretende eliminar o que chamou de uma falsa antinomia entre políticas de redistribuição e políticas de reconhecimento. A autora correlaciona as políticas de identidade com a questão do status, que ela retoma como uma categoria para se compreender a forma como a questão cultural se articula com as exigências da justiça não só como reconhecimento, mas também como redistribuição e participação. Articulado a isso, ela correlaciona a questão econômica, as exigências de classe em torno da redistribuição, as demandas culturais, de gênero e etnia. Trata-se de investigar como medidas redistributivas promovem ou não reconhecimento e como políticas de reconhecimento produzem ou não redistribuição e de que maneira essas formas de garantir justiça possibilitam uma maior ou menor "participação". Assim cabe inquirir quando uma medida redistributiva, por exemplo, algum tipo de renda mínima, estigmatiza um determinado grupo, afetando sua autoestima, ou quando uma política de reconhecimento dirigida a uma "minoria", mulheres, negros, homossexuais, índios, entre outros, promove alguma forma de redistribuição, na medida em que e na proporção segundo a qual isso daria acesso a rendas e recursos.

A autora mostra que há questões étnicas, raciais e de gênero que especificam formas de injustiças econômicas: gender-especific, 'race'-specific, and sex-specific forms of economics injustice. São formas de injustiça que tradicionalmente não tinham sido levadas em conta, especialmente pelas reivindicações dos movimentos de classe (FRASER, 2003). Ela questiona também a forma como os que advogam políticas da diversidade não levam em conta a dimensão redistributiva do reconhecimento (idem, ibid.).

Em relação ao status, Fraser destaca que padrões de valores culturais - incorporados nas instituições, em sociedades onde de certa forma prevalece algum tipo de estamento ou ordem hierárquica simbólica relacionada à origem social, etnia, gênero, religião e de mérito, que definem hierarquias de mando e obediência - produzem injustiça ligada ao não reconhecimento. $O$ desrespeito ligado ao status estaria intrincado com a injustiça econômica, cuja correção exige redistribuição (idem, ibid.). Para superar, por exemplo, injustiças ligadas ao racismo seriam necessárias medidas de redistribuição e reconhecimento ao mesmo tempo (ibid.). Certos grupos sofrem tanto devido à má distribuição quanto ao não reconhecimento, pois estas formas de injustiças têm efeito direto uma sobre a outra. Fraser destaca ainda que, em muitos casos, nem medidas de redistribuição isoladas nem políticas de 
reconhecimentos sozinhas podem produzir transformações significativa no âmbito da emancipação dos grupos injustiçados, sobretudo quando são incapazes de promoverem a participação.

A participação é a base normativa posta por Fraser para investigar a des/articulação teórica e prática entre redistribuição e reconhecimento. Com sua concepção de status model of recognition, ela aponta os limites do reconhecimento baseado na autorrealização (Taylor e Honneth). A autora não enfoca o não reconhecimento nem como uma deformação psíquica, nem como uma forma de impedimento de autorrealização ética, mas como bloqueio institucionalizado que impede a igual participação enquanto parceiro nos diversos âmbitos da vida social (FRASER, op. cit.).

A justiça significa então promover a paridade de participação, sobretudo, nas esferas públicas onde as políticas são definidas. Trata-se de eliminar a institucionalização (deinstitutionalize) dos padrões de valores culturais que impedem a participação paritária, substituindo-os por padrões que promovam tal participação (idem, ibid.). Daí a importância da democracia como debate sobre quais formas de interação devem existir, que tipo de status quo social perverso certas práticas fomentam e como promover novas práticas aceitáveis do ponto de vista da justiça. Cabe à democracia, enfim, promover o debate sobre o debate público e as formas de participação nele (metanível de debate ou exigências deliberativas de segunda ordem). A participação no debate público deve ser ampliada para incorporar todos os concernidos pelas políticas em questão, no sentido de avaliar o mérito da redistribuição e do reconhecimento e quem deve contribuir ou se beneficiar com eles. Assim, a deliberação democrática justa exige reconhecimento recíproco e justa redistribuição. Sem isso, certos indivíduos e grupos não superarão bloqueios (vergonha, falta de confiança em si, de estima de si e de respeito de si), nem terão recursos (renda, tempo disponível) para participar como parceiros no debate público.

Fraser (2003) mostra a diversidade das possibilidades de articulação das categorias normativas. Isso tem efeitos teóricos e práticos no campo da produção de políticas educacionais, sobretudo para se compreender como elas se justificam e se fundamentam. Os arranjos das categorias normativas possibilitam investigar as políticas educacionais desde o seu nascedouro até o que elas, posteriormente, efetivam ou não socialmente. A LDB (Lei n. 9.394, de 1996) e a Conferência Nacional de Educação (Conae), de 2010, expressam embates que resultaram em marcos normativos cristalizados em seus textos, que redefinem exigências para as políticas educacionais. Assim, pode-se rastrear o discurso normativo que perpassa tais documentos, o que muitas vezes não se apresenta de forma explicita e articulada no momento de sua construção e também de suas interpretações nos contextos da gestão da educação. 


\section{Questões normativas na LDB e na Conae}

A política do reconhecimento tem sido apresentada como uma realidade no âmbito da educação brasileira. Pelo menos, assim o Documento Final da Conae quer fazer crer, quando afirma que, na atualidade, no Brasil, mais de cinquenta universidades públicas e privadas possuíam alguma forma de ação afirmativa, que constituiriam políticas que "têm como base a justiça social e o reconhecimento" (CONAE, 2010, p. 129). Destaca-se que isso decorreu da pressão dos movimentos sociais que levaram o Estado brasileiro a implementar tais políticas. O discurso da Conae faz eco ao que se diz no âmbito da Secretaria de Políticas de Promoção da Igualdade Racial (Seppir).

No âmbito da educação, um marco para a política do reconhecimento no Brasil foi a criação da Secretaria de Educação Continuada, Alfabetização, Diversidade e Inclusão (Secad), em julho de 2004, pelo Ministério da Educação. Nela estão reunidas as ações ligadas à alfabetização e educação de jovens e adultos, à educação do campo, à educação ambiental, à educação em direitos humanos, à educação escolar indígena e à diversidade étnico-racial, temas antes dispersos em outras secretarias. Segundo o Plano Nacional de Implementação das Diretrizes Curriculares Nacionais para Educação das Relações Étnico-Raciais e para o Ensino de História e Cultura Afro-brasileira e Africana (BRASIL, 2009), a Secad é uma "arquitetura institucional capaz de enfrentar as múltiplas dimensões da desigualdade educacional do país", sobretudo para "desenvolver e implementar políticas de inclusão educacional, considerando as especificidades das desigualdades brasileiras e assegurando o respeito e valorização dos múltiplos contornos de nossa diversidade étnico-racial, cultural, de gênero, social, ambiental e regional" (BRASIL, op. cit., p. 15). A Secad expressa, de certa forma, no âmbito político institucional exigências normativas ligadas ou não ao reconhecimento. Isso pode ser rastreado também no que se propõe em termos do currículo e da avaliação, tal como a LDB n. 9.394/96 normatizou. Contudo, tais exigências podem ser mais bem compreendidas a partir de uma abordagem mais abrangente da referida Lei.

O modo como a LDB define a educação indica que a formação diz respeito a espaços sociais diversos, marcados por questões de justiça. Segundo a referida Lei, em seu artigo 1, a "educação abrange os processos formativos que se desenvolvem na vida familiar, na convivência humana, no trabalho, nas instituições de ensino e pesquisa, nos movimentos sociais e organizações da sociedade civil e nas manifestações culturais". As bases normativas apresentadas permitem analisar essa concepção de educação.

As instituições sociais, na LDB, se apresentam, de certo modo, como espaço de reconhecimento, redistribuição e participação. A família é marcada pela esfera do amor e das exigências de justiça ligadas ao gênero, à distribuição. Que tipo de 
benefícios donas de casas teriam ou não direitos em termos de renda, previdência social e demais questões de bem-estar? Quais famílias deveriam receber recursos para manter suas crianças nas escolas e para ter acesso à cultura e às tecnologias que são decisivas em termos de diferenciação do perfil intelectual dos alunos? Por sua vez, o mundo do trabalho está permeado por questões de distribuição, de reconhecimento de diferenças sexuais, étnicas e de acesso a cargos e níveis salariais, bem como de participação na gestão coletiva do trabalho e nos "lucros".

Da mesma forma, as organizações da sociedade civil são centros por excelência de articulação de exigências em torno de reconhecimento, redistribuição e participação. As manifestações culturais são perpassadas também pela questão da justiça: quais grupos têm acesso à mídia? Quais atividades culturais devem ou não receber apoio público? Até que ponto deve-se aceitar a desigualdade de acesso à mídia por parte de grupos discriminados, cujas manifestações são tidas como inferiores ou inadequadas? Até que ponto grupos podem também manter escolas que difundam seus valores? Em relação às instituições de ensino e pesquisa, quem deve ter acesso a formação superior em universidades? Como garantir tal acesso a grupos e povos que historicamente não tiveram e ainda não tem acesso a elas? $\mathrm{O}$ que deve ser pesquisado e como selecionar pesquisadores e projetos? Como definir o "mérito" ou "relevância" quando se trata de destinar recursos públicos para as pesquisas? Até que ponto isso pode considerar questões de redistribuição, reconhecimento e participação ou deve ser feito como se a ciência fosse índice de si mesma, sem consideração com questões normativas externas?

Dessa forma, o conceito de educação da Lei n. 9.394 aponta para processos formativos que ocorrem nos âmbitos perpassados pelas questões de justiça. Contudo, a LDB regula a educação escolar e as instituições de ensino onde ela é predominante. A questão de quem pode oferecer educação e quem deve financiá-la ou receber recursos públicos é central para se discutir a justiça de fundo na educação, tanto no que diz respeito aos conteúdos, valores e tipo de homem a ser formado (ou seja, ao bem, pois não é possível neutralidade em relação a isso), quanto a quem deve contribuir mais para com o financiamento público e quem deve receber mais recursos oficiais. Mesmo a discussão em torno da existência ou não de escolas privadas é uma questão normativa, pois envolve não apenas interesses materiais, mas também valores e concepções de mundo.

$\mathrm{Na}$ escola, as questões de justiça estão constantemente presentes e sua discussão torna-se cada vez mais necessária para a gestão democrática da educação. Isso a perpassa em todos os seus momentos, desde a elaboração de seu projeto político-pedagógico, do que será privilegiado nele, até questões relacionadas ao tratamento de indivíduos e grupos de estudantes com características distintas. Frente a isso, até que ponto flexibilizar o currículo para que ele atenda exigências 
de reconhecimento? Como fazer isso de modo democrático? Decisivas são também as questões referentes aos recursos que as escolas necessitam, ao tratamento dado ao professor, e aos demais funcionários da escola, sua carreira, as exigências de condições dignas de trabalho, de formação continuada e de salário, bem como de participação nos diversos níveis de gestão da educação e de formulação de políticas educacionais. Enfim, como definir políticas que promovam o reconhecimento social do professor? Isso pode ser feito apenas com aumento de salários ou/e com mudanças de valores e percepções em torno da importância do trabalho e da pessoa do professor, garantindo-lhe efetiva participação nos rumos da educação e no controle de seu próprio trabalho, base de sua autorrealização?

Em seu $\S 2^{\circ}$, a LDB diz que "a educação escolar deverá vincular-se ao mundo do trabalho e à prática social". A qualificação profissional é fundamental em termos de preparar a pessoa para ter acesso a empregos e cargos e, com isso, a recursos. A questão é definir até que ponto a educação tem contribuído para promover a igualdade de oportunidades, tão exaltada pela justiça liberal, ou tem acentuado a iniquidade em torno do preparo para o mundo do trabalho, para poder redefinir políticas que poderiam corrigir essa forma de injustiça. Em relação às práticas sociais, pode-se inquirir em que sentido a escola tem contribuído para inverter as condições deterioradas de reconhecimento social e em que sentido as práticas da comunidade escolar promovem uma formação não distorcida, em ternos de propiciar experiências positivas de reconhecimento?

A escola, no mundo atual, é decisiva para a autorrealização humana, pois é perpassada pela interação afetiva, pelo reconhecimento de direitos e por práticas intersubjetivas de solidariedade. Pode-se falar da escola tanto como um espaço prépolítico de expressão de conflitos de reconhecimentos (basta ver a questão da violência na escola), como também um espaço público onde as mais diversas questões podem ser oficialmente discutidas, de acordo com as regras e procedimentos de participação democrática válidos para os colegiados gestores da educação.

A LDB garante que a educação se paute pela liberdade e solidariedade, visando o pleno desenvolvimento do educando, formando para a cidadania e o mundo do trabalho. Contudo, não se define qual concepção de autodeterminação ela exige, pois não estabelece uma conexão normativa necessária entre a liberdade e a solidariedade. Isso afeta também a compreensão de que tipo de desenvolvimento pleno está se exigindo. Trata-se de desenvolver a racionalidade e a razoabilidade liberal, destacando o sentido vazio e desengajado delas, ou de propiciar condições substantivas de formação? Neste caso, deve-se levar em conta a relação da escola com as esferas de reconhecimentos mais amplas, dando a formação plena o significado da autorrealização que alcance a esfera da solidariedade não liberal, onde o respeito pelas diferenças é meramente estratégico e/ou indiferente. 
Formar para que tipo de cidadania? Como mera forma de se adequar ao mercado e de cumprir rituais cívicos da democracia representativa? Ou como atuação democrática nas diversas esferas públicas, no sentido tanto de expandir os espaços deliberativos como de lutar por condições de participação justas que exigem políticas de distribuição e reconhecimento? Até que ponto a formação para a cidadania suporta um aprendizado político engajado na transformação do mundo do trabalho (e não meramente para qualificar e adequar pessoas ao mercado) e, com ele, o atual padrão patológico de civilização capitalista?

A partir da base dada pela atual LDB e das concepções de justiça discutidas, pode-se investigar a natureza normativa das políticas públicas para a educação e de seus efeitos em termos de distribuição, reconhecimento e participação. Que efeitos "normativos" estão produzindo o Plano Nacional de Implementação das Diretrizes Curriculares Nacionais para a Educação das Relações Étnico-Raciais e para o Ensino de História e Cultura Afro-brasileira e Africana, as Leis n. 10.639/2003 e n. 11.645/08 e o Programa Bolsa-Família? Como aqueles que são, de certo modo, beneficiados com tais políticas têm percebido a escola como um espaço formativo em termos de redistribuição, reconhecimento e participação?

Os marcos normativos que orientaram a LDB nunca foram consensuais. A Conae foi um momento de rediscutir as bases do pacto educacional no Brasil. Esta Conferência foi um dos mais ricos momentos da democratização da política educacional no Brasil. Seu Documento Final é uma base normativa inestimável que, durante um bom tempo, deve orientar as políticas públicas e a luta no campo da educação no Brasil (CONAE, 2010).

Destaca-se o Eixo VI do Documento Final, cujo título é Justiça social, educação e trabalho: inclusão, diversidade e igualdade. Suas pretensões abarcam um amplo leque de questões normativas, pois se exige a garantia de uma educação pautada na justiça social; consideração do mundo do trabalho para além da teoria do capital humano; reconhecimento e diálogo com a diversidade; ampliação da noção de inclusão e igualdade social. Afirma-se que isso deve ser feito como um enfrentamento do desafio de superar uma sociedade marcada por profundas desigualdades sociais, de classe, de gênero, étnico-raciais, geracionais, e de pessoa com deficiência.

O Eixo VI agrega as seguintes temáticas: questão étnico-racial, quilombolas, indígena, do campo, ciganos, das pessoas com deficiência, educação ambiental, crianças, adolescentes e jovens em situação de risco, educação de jovens e adultos e educação profissional. Ao se inserir a questão da formação profissional na discussão da justiça e da diversidade, o texto final da Conae trouxe uma série de inquietações. As bases normativas apresentadas ajudam a compreender o significado dessa inserção, sobretudo, dentro do atual contexto ético-político nacional. Contudo, essa investigação não pode ser feita no curto espaço deste texto. 
A Conae afirma que não há incompatibilidade entre a luta pelo reconhecimento e pela redistribuição: "a luta pelo reconhecimento e o direito à diversidade não se opõe à luta pela superação das desigualdades sociais" (CONAE, 2010, p. 128). Assim é identificada uma correlação entre o reconhecimento e a redistribuição, entre a diferença e a desigualdade. Entende-se que as diferenças, quando geram discriminação, podem aprofundar a desigualdade. O que se questiona é a "forma desigual" pela qual as diferenças são historicamente tratadas na escola e nas políticas públicas. Trata-se de uma "luta" que alerta para as consequências do desconhecimento da diversidade e do tratamento das diferenças de forma discriminatória. Isso aumentaria "ainda mais a desigualdade", num processo "que se propaga via a conjugação de relações assimétricas de classe, étnico-raciais, gênero, diversidade religiosa, idade, orientação sexual e cidade-campo" (idem, ibid.).

\section{Considerações finais}

A LDB, Lei n. 9.394/96, consolida o que deve orientar o país em termos de educação, indicando normas específicas para os entes federados, as instituições de ensino e os profissionais da educação. A base ética dada nos princípios para a educação não especifica um horizonte normativo maior, pelo menos este não está limpidamente definido, expressando, portanto, um não compromisso com alguma forma substantiva de bem. A Conae rediscutiu os marcos normativos da educação brasileira, explicitando bases normativas e apontando para novas exigências que deveriam orientar não só o Plano Nacional de Educação. Nela, o reconhecimento apresenta-se com um eixo normativo ao lado da redistribuição e da participação. Cabe ressaltar que isso não foi feito a partir da explicitação sistemática de uma abordagem normativa, sendo a Conferência mais um momento de expressão de sentimentos e de experiências de desrespeito e injustiça que perpassam a realidade educacional no Brasil, mesmo quando indicadores rigorosos sobre a educação brasileira foram apresentados por renomados especialistas.

A discussão normativa, na prática, permite abordar as políticas em termos de definir o que é necessário, prioritário e de como isso dever ser efetivado para realizar certo ideário de sociedade. Isso permite entender o que se pode cobrar e esperar das políticas de Estado e das exigências de qualidade social da educação. Teoricamente, essa prática permite testar a força heurística e normativa de categorias como redistribuição, participação e reconhecimento, revelando suas possibilidades e limites para a práxis no âmbito da educação. Frente a isso, questões normativas na forma de ideários de justiça surgem no âmbito da LDB e no Documento Final da Conae.

Segundo a Conae, cabe à educação promover o "desenvolvimento e a apreensão de saberes científicos, artísticos, tecnológicos, sociais e históricos, compreendendo as 
necessidades do mundo do trabalho, os elementos materiais e a subjetividade humana." (CONAE, op. cit., p. 41). Extrinsecamente, ou em seus efeitos históricos, a qualidade social da educação pode ser correlacionada com exigências de normatividade, tais como as apresentadas anteriormente. Cabe investigar até que ponto a experiência formativa dentro dos marcos das políticas públicas educacionais possibilita ou é acompanhada de efetivação de justiça social mapeáveis como redistribuição, participação ou reconhecimento. Isso exige pesquisas empíricas orientadas pelas categorias da justiça social que são pressupostas nas políticas educacionais, que abarcam os mais diversos níveis e modalidades da educação.

As discussões a respeito dos fins da educação têm afirmado, no âmbito da avaliação, a qualidade social da formação como bem a ser promovido publicamente, tal como é apontado no Eixo II da Conae sobre a qualidade da educação, gestão democrática e avaliação. Assegurar a construção da qualidade social inerente ao processo educativo não pode ser feito sem explicitar os valores e fins que se quer promover e alcançar. A qualidade social não pode ser aferida apenas por indicadores numéricos para se avaliar metas tecnicamente estabelecidas. Sem levar em conta a discussão a respeito do que a educação socialmente efetiva (em termos de redistribuição, participação e reconhecimento) com tais metas, explicitando uma base normativa para julgá-la, em nada se poderia avançar politicamente em relação à qualidade total na educação, discurso que tem sido repudiado, no âmbito das forças não conservadoras, como finalidade das políticas públicas educacionais no Brasil.

\section{Referências}

BRASIL. Lei n. 9.394, de 20 de dezembro de 1996. Estabelece as diretrizes e bases da Educação Nacional. Diário Oficial da União, Brasília, DF, 23 dez. 1996.

BRASIL. Ministério da Educação. Plano Nacional de Implementação das Diretrizes Curriculares Nacionais para Educação das Relações Etnicorraciais e para o Ensino de História e Cultura Afro-brasileira e Africana. Brasília, DF: Seppir, 2009.

CONFERENCIA NACIONAL DE EDUCAÇÃO (CONAE), 2010, Brasília, DF. Documento final 2010. Brasília, DF: MEC, 2010.

FISCHERBACH, F. Fichte et Hegel: la reconnaissance. Paris: PUF, 1999.

FORST, R. Contextos da justiça. São Paulo: Boitempo, 2010.

FRASER, N. Social justice in age of identity politics: redistribution, recognition and participation. In: FRASER, N.; HONNETH, A. Redistribution or recognition?: a political-philosophical exchange. London: Verso, 2003. p. 7-109. 
HONNETH, A. Luta por reconhecimento: a gramática moral dos conflitos sociais. São Paulo: Editora 34, 2003a.

HONNETH, A. Resdistribution as recognition: a response to Fraser. In: FRASER, N.; HONNETH, A. Redistribution or recognition?: a political-philosophical exchange. London: Verso, 2003b. p. 110-197.

HONNETH, A. Sofrimento e indeterminação: uma reatualização de filosofia do direito de Hegel. São Paulo: Esfera Pública, 2007.

HONNETH, A. Disrespect: the normative foundations of critical theory. Cambrigde; Malden: Political, 2008.

KORSGAARD, C. The sources of normativity. Cambridge: Cambridge Universty, 1996.

KYMLICKA, W. Filosofia política contemporânea. São Paulo: Martins Fontes, 2006.

RAWLS, J. A theory of justice. London: Oxford University, 1971.

TAYLOR, C. Argumentos filosóficos. São Paulo: Loyola, 2000.

VAN PARIJS, P. O que é uma sociedade justa? São Paulo: Ática, 1997.

WERLE, D.; MELO, R. Introdução: teoria crítica, teorias da justiça e a "reatualização" de Hegel. In: HONNETH, A. Sofrimento e indeterminação: uma reatualização de filosofia do direito de Hegel. São Paulo: Esfera Pública, 2007.

Recebido em 25 de abril de 2011.

Aprovado em 26 de outubro de 2012. 